\title{
Pattern of Angulations and Common Indications for Extraction of Impacted Mandibular Third Molar at KMU-Institute of Dental Sciences, Kohat
}

\author{
Tariq Sardar 1, Gulrukh Sheikh 2, Saddique Aslam ${ }^{3}$, Numan Muhammad Khan ${ }^{4}$, Javed Akhtar Rana 5 \\ ${ }^{1}$ Senior Registrar, Department of Oral and Maxillofacial Surgery, KMU Institute of Dental Sciences, Kohat. \\ ${ }^{2}$ Clinical Attaché, Department of Periodontology, Khyber College of Dentistry, Peshawar. \\ ${ }^{3}$ Professor \& Head, Department of Oral and Maxillofacial Surgery, KMU Institute of Dental Sciences, Kohat. \\ ${ }^{4}$ Registrar, Department of Oral and Maxillofacial Surgery, KMU Institute of Dental Sciences, Kohat. \\ ${ }_{5}^{5}$ Post Graduate Resident, Department of Oral and Maxillofacial Surgery, Shaheed Zulfiqar Ali Bhutto Medical University, Islamabad
}

ABSTRACT

Background: The extraction of an impacted mandibular third molar (MTM), with associated pathologies or clinical manifestations is an important and one of the most frequent decisions in dentistry. The angle formed by the longitudinal axis of second and third molar is used to determine angulation of impacted MTM. The aim of this study was to identify the pattern of angulations of impacted mandibular third molar and common indications for extraction associated with these angulations.

Material and Methods: This descriptive cross-sectional study was carried out at Department of Oral \& Maxillofacial Surgery, Khyber Medical University Institute of Dental Sciences, Kohat, Khyber Pakhtunkhwa (KP) from November 2017 to July 2018. A total of 349 patients presenting with impacted mandibular third molars were included in this study. Name, age, gender, address, the angulation of the impacted tooth and the indication for extraction of the impacted tooth were recorded. Data comprising of qualitative and quantitative variables were analyzed using SPSS version 17.

Results: Out of 349 patients, 206 were male and 143 females, with the male to female ratio of 1.4:1. The age range of the patients was from 18 years to 60 years with a mean age of $26 \pm 6$ years. The most common age group with impacted third molar was $\leq 25$ years followed by 26 to 30 years' age group. The most common angulation was mesioangular followed by vertical, horizontal and distoangular impacted mandibular third molar. Pericoronitis was the most common indication for extraction in all angulations except horizontal impaction where root resorption of the second molar was more common.

Conclusion: Mesioangular is the most common angulation in impacted mandibular third molars. Pericoronitis is the main indication for all angulations of impacted mandibular third molars except horizontal angulation, occurring mostly in the third decade of life.

Key words: Angulation, Impacted tooth, Third molar, Tooth extraction

Authors' Contribution:

1,2 Conception, synthesis, planning of

research and manuscript writing ${ }^{3}$

Interpretation, discussion, ${ }^{4,5}$ Active

participation in data collection

Data analysis.

Cite this article. Sardar T, Sheikh G, Aslam S, Khan NM, Rana JA. Pattern of Angulations and

Common Indications for Extraction of Impacted Mandibular Third Molar at KMU-Institute of

Dental Science, Kohat. J Islamabad Med Dental Coll.2019; 8(2):79-83

$\begin{array}{ll}\text { Correspondence: } & \text { Article info: } \\ \text { Tariq Sardar } & \text { Received: October 24, } 2018 \\ \text { Email: drtari561@gmail.com } & \text { Accepted: April 2, 2019 }\end{array}$

Funding Source: Nil

Conflict of Interest: Nil

\section{Introduction}

An impacted tooth is one that fails to erupt into its normal functioning position in the mouth within its expected time. ${ }^{1}$ Different reasons for a tooth becoming impacted include dense overlying hard and soft tissue, lack of space, abnormal eruption path, unusual positioning of tooth bud and associated pathological lesions. ${ }^{2}$ General factors like genetic abnormality, rickets, anemia, irradiation, congenital syphilis, tuberculosis, malnutrition and cretinism also cause impaction. ${ }^{3}$ The mandibuar third molar (MTM) is the most frequently impacted tooth 
followed by maxillary third molar and maxillary canine. ${ }^{4-6}$ The angle formed by the longitudinal axes of second and third molar is used to determine angulation of impacted MTM. Thus, the impaction can be mesioangular, distoangular, horizontal, transverse or vertically angulated. 5,7

Whether to extract or retain an impacted MTM is an important and one of the most frequent decisions in dentistry and oral surgery. ${ }^{8,9}$ There is complete consensus on the removal of impacted third molar with associated pathologies or clinical manifestations but their prophylactic removal is still a subject of debate. ${ }^{10,11}$ The pathologies associated with impacted MTM include pericoronitis, carries/pulpitis of second or third molar, periodontal problems, root resorption of second molar, neurogenic pain and cyst or tumors. ${ }^{4,8,12}$ In addition to associated pathologies, these impacted molars may need removal for orthodontic and prosthodontic or restorative reasons. ${ }^{13,14}$ The aim of this study was to analyze the pattern of angulation of MTM and the common indications for removal associated with different angulations of these impacted teeth at KMU-IDS, Kohat

\section{Material and Methods}

This descriptive cross-sectional study was conducted from November 2017 to July 2018 in the department of Oral and Maxillofacial Surgery, at KMU-Institute of Dental Sciences, Kohat, KP. A total of 349 patients, aged 18 years and above, presenting to the outpatient department with impacted mandibular third molar were included in this study. After obtaining approval of the ethical committee of the institution, written informed consent from the patients was taken.

Inclusion criteria included all patients who required extraction of impacted mandibular third molars associated with pathologies or asymptomatic mandibular third molars requiring extraction for orthodontic or prosthodontic reasons. Patients younger than 18 years, any maxillofacial trauma, with craniofacial anomalies and syndromes like Apert syndrome, cleidocranial dysostosis and disease free asymptomatic mandibular third molars were excluded from the study.
The parameters recorded included the age, gender, the angulation of the impacted tooth and the indication for extraction of the impacted tooth. The angulation of an impacted third molar was determined on the basis of Winter's classification with reference to the angle formed by the longitudinal axes of the second and third molars. The angulation and indication for extraction was determined on the basis of history, clinical examination and radiographs that included a standard periapical radiograph supplemented by orthopantomogram where necessary. Data was analyzed in SPSS version 17. The qualitative variables in the demographic data like gender, patterns of angulation and indications for extraction were presented as proportions and percentages and quantitative variables like age were presented as means and standard deviation.

\section{Results}

A total of 349 patients who reported for extraction of impacted mandibular third molar were included in this study. Most of them were males $(n=206,59 \%)$ with a male to female ratio of 1.4:1. The age ranged from 18 years to 60 years with a mean age of $26 \pm 6$ years. Most of the patients belonged to age group 25 years and below $(57 \%)$ followed by $26-30$ years' age group $(24.1 \%)$. Details of different age groups are given in Table I.

\begin{tabular}{|l|c|}
\hline \multicolumn{2}{|c|}{$\begin{array}{c}\text { Table I: Frequency Distribution of Impacted Third Molars } \\
\text { according to Age Groups }\end{array}$} \\
\hline $\begin{array}{c}\text { Age groups } \\
\text { (years) }\end{array}$ & $\begin{array}{c}\text { Impacted Mandibular Third Molars } \\
\mathbf{n}(\%)\end{array}$ \\
\hline 25 and below & $199(57)$ \\
\hline $26-30$ & $84(24.1)$ \\
\hline 31 to 35 & $38(10.9)$ \\
\hline 36 to 40 & $12(3.4)$ \\
\hline 41 to 45 & $10(2.9)$ \\
\hline 46 and above & $6(1.7)$ \\
\hline Total & 349 \\
\hline
\end{tabular}

Mesioangular impaction (48.7\%) was the most common amongst the patients who reported for extraction of impacted mandibular third molar at KMU-IDS. This was followed by vertical impaction (28.7\%), distoangular impaction (12.6\%) and horizontal impaction (10\%) of the mandibular third molar, respectively. 


\begin{tabular}{|l|c|}
\hline \multicolumn{2}{|c|}{$\begin{array}{c}\text { Table Il: Frequency distribution of indications for extraction of } \\
\text { Impandibular Third Molars }\end{array}$} \\
\hline Indications for Extraction & $\begin{array}{c}\text { Impacted Mandibular Third } \\
\text { Molars } \\
\text { n (\%) }\end{array}$ \\
\hline Pericoronitis & $169(48.4)$ \\
\hline $2^{\text {nd }}$ molar caries & $48(13.8)$ \\
\hline $3^{\text {rd }}$ molar caries/Pulpitis & $52(14.9)$ \\
\hline Periodontal Problems & $31(8.9)$ \\
\hline Root Resorption (2nd Molar) & $17(4.9)$ \\
\hline Cyst/Tumor & $2(0.6)$ \\
\hline Pain of Unknown Origin & $28(6)$ \\
\hline Orthodontic Purpose & $7(2)$ \\
\hline Prosthodontic Purpose & $2(0.6)$ \\
\hline Total & 349 \\
\hline
\end{tabular}

The most frequent indication for extraction of MTM was pericoronitis $(48.4 \%)$. Other common indications for extraction of impacted MTM are shown in Table II.

Pericoronitis was the most common indication for extraction of MTM associated with all angulations except horizontal impaction, which commonly caused root resorption of the second molar. The relationship of different indications for extraction with various angulations is shown in Table III

\section{Discussion}

Third molar extractions are frequently carried out procedures performed by oral surgeons and an indication for referral to Oral and Maxillofacial surgeons. This study was conducted at Oral \& Maxillofacial Surgery Department, KMU-IDS, Kohat in which 349 patients with impacted MTM were observed. In this study, majority of the patients $(59 \%)$ were males while $41 \%$ patients were females with an age range of 18 to 60 years. This is in contrast with other studies ${ }^{15,16}$ from around the world that reported a higher proportion of female patients while local studies ${ }^{17,18}$ showed similar male preponderance. The explanation for higher incidence of male patients may be attributed to the male dominant society and cultural restriction on females where males have more opportunities to seek medical and dental advice as compared to females who usually require male attendants to seek any treatment. The most common age group at the time of presentation was 25 years or less followed by
$25-30$ years $(24.1 \%)$ declining to only $1.7 \%$ in 45 years or more age group. Thus, most of the patients belonged to the $3^{\text {rd }}$ decade of life with a sharp decline in older age groups. This sharp decline may be explained by the removal of impacted mandibular molars at younger age especially in the third decade of life. Similar high incidence of impacted MTM in the third decade of life has been reported by other studies as well. 1,8,18

The current study showed that the mesioangular impacted MTM was the most common (38.7\%) followed by vertical (28.7\%), distoangular (12.6\%) and horizontal (10\%) impactions. Similar results were reported in other studies as well. ${ }^{18-20}$

Pericoronitis was the main indication for extraction (48.4 $\%$ ) of mesioangular (most common), vertical, distoangular and horizontal impactions respectively. This is in contrast to other studies, which show high incidence of pericoronitis associated with vertical impactions. ${ }^{18,21} \mathrm{We}$ assume that this high incidence of pericoronitis with mesioangular impaction in our study might be due to a higher percentage of these impactions in our study population. The net percentage of pericoronitis is the highest for distoangular impaction followed by vertical and mesioangular.

The second most common reason for removal of the impacted MTM was dental caries of third molar itself followed by caries and pulpitis of the second mandibular molar. Third molar caries was common with vertical impaction while second molar caries was common with mesioangular impaction. These observations are similar to other studies conducted in Libya, Nigeria and Pakistan. ${ }^{15,16,18}$ This high incidence of caries may be due to the food entrapment and difficulty in maintaining oral hygiene due to relative inaccessibility to this area.

Periodontal problems were the fourth common indication for removal of impacted mandibular molar in our study. Most of these periodontal problems were associated with mesioangular impacted MTM which may be due to the food entrapment and bacterial colonization and inability to clean the area properly. Similar results were reported in other studies as well. 18,20 Two important reasons for removal of impacted MTM are to preserve periodontal health or treat existing periodontitis. The association of visible third molar with periodontal conditions in young adults indicates negative impact on periodontal health. 


\begin{tabular}{|l|c|c|c|c|c|}
\hline \multicolumn{5}{|c|}{ Table III: Frequency of different indications for extraction in relation to angulations } \\
\hline \multirow{5}{*}{ Indications for Extraction } & \multicolumn{5}{c|}{ Angulations } \\
\cline { 2 - 6 } & $\begin{array}{c}\text { Mesioangular } \\
\mathbf{n}\end{array}$ & $\begin{array}{c}\text { Horizontal } \\
\mathbf{n}\end{array}$ & $\begin{array}{c}\text { Vertical } \\
\mathbf{n}\end{array}$ & $\begin{array}{c}\text { Distoangular } \\
\mathbf{n}\end{array}$ & $\begin{array}{c}\text { Total } \\
\mathbf{n}(\%)\end{array}$ \\
\hline Pericoronitis & 74 & 5 & 56 & 34 & $169(48.4)$ \\
\hline $2^{\text {nd }}$ Molar Caries & 38 & 4 & 5 & 1 & $48(13.75)$ \\
\hline $3^{\text {rd Molar Caries/Pulpitis }}$ & 20 & 5 & 23 & 4 & $52(14.9)$ \\
\hline Periodontal Problems & 25 & 4 & 2 & 0 & $31(8.88)$ \\
\hline Root Resorption (2nd Molar) & 5 & 11 & 1 & 0 & $17(4.87)$ \\
\hline Cyst/Tumor & 1 & 0 & 1 & 0 & $2(0.57)$ \\
\hline Pain of Unknown origin & 2 & 3 & 11 & 5 & $21(6)$ \\
\hline Orthodontic Purpose & 5 & 2 & 0 & 0 & $7(2)$ \\
\hline Prosthodontic Purpose & 0 & 1 & 1 & 0 & $2(0.57)$ \\
\hline Total & 170 & 35 & 100 & 44 & 349 \\
\hline
\end{tabular}

Root resorption of the second mandibular molar was more commonly reported with horizontal angulation of the impacted MTM in our study. Similar results of root resorption with horizontal and mesioangular impactions were reported in other studies as well. ${ }^{20,22}$ This root resorption associated with horizontally impacted tooth is due to the pressure exerted by the crown of impacted tooth. In our study, only two patients $(0.6 \%)$ reported with cyst/tumor, associated one each with mesioangular and vertical impacted tooth. This percentage is lower than other studies carried out by Ishfaq et al $(2 \%)^{18}$ and Krishnan et al (5\%)..$^{15}$

About 21 patients reported for extraction of MTM with undiagnosed pain. Most of these patients (11) had vertical impacted tooth. Similar indication of undiagnosed pain was reported in other studies as well. 16,18,23 The undiagnosed pain may be attributed to the lack of more advanced imaging techniques like computed tomography scan, magnetic resonance imaging, cone beam computed tomography etc in our set-up and the unwillingness of patients to undergo further investigation before extracting the impacted tooth. Most of these patients have already gone to a general dentist who had pointed out the impacted tooth as a possible cause of their pain. Similarly, 07 patients were referred by orthodontist for extraction of the third molar while 02 patients extracted the impacted tooth for fabrication of denture. Extraction of impacted MTM for orthodontic purposes has been reported in other studies as well. ${ }^{15,16,18} .19$

\section{Conclusion}

Most of the patients were young males in the third decade of life. Mesioangular impaction was the most common impacted tooth, while pericoronitis was the most common indication for removal of the impacted tooth associated with all angulations except horizontal angulation where root resorption was more common.

\section{References}

1. Hassan $\mathrm{AH}$. Pattern of third molar impaction in a Saudi population Clin Cosmet Investig Dent. 2010;2: 109-13. doi: 10.2147/CCIDEN.S12394

2. Ishihara $Y$, Kamioka $H$, Yamamoto TT, Yamashiro $T$. Patients with nonsyndromic bilateral and multiple impacted teeth and dentigerous cysts. Am J Orthod Dentofacial Orthop. 2012; 141(2): 228-41. doi: 10.1016/j.ajodo.2010.02.043

3. Brakus I, Filipovic Z, Boric R, Siber S, Svegar D, Kuna T. Analysis of impacted and retained teeth operated at the department of Oral Surgery, School of Dental Medicine, Zagreb. Coll Antropol. 2010;34(Suppl 1):229-33. PMID: 20402324

4. Chu FC, Li TK, Lui VK, Newsome PR, Chow RL, Cheung LK. Prevalence of impacted teeth and associated pathologies - a radiographic study of the Hong Kong Chinese population. Hong Kong Med J. 2003;9(3):158-63. PMID: 12777649 
5. Tarzona BA, Paredes VB, Llamas JM, Cibrian RE, Gandia $\mathrm{JL}$. Influence of first and second premolar extractions or non-extraction treatments on mandibular third molar angulation and position. A comparative study. Med Oral Pathol Oral Cir Bucal. 2010;15(5): 760-66. doi: 10.4317/medoral.15.e760

6. Zuccati GC, Doldo T. Multiple impactions in an adolescent girl. Am J Orthod Dentofacial Orthop. 2010;137(4):16372.doi: 10.1016/j.ajodo.2008.03.035.

7. Quek SL, Tay CK, Tay KH, Toh SL, Lim KC. Pattern of third molar impaction in Singapore Chinese population: a retrospective radiographic survey. Int J Oral Maxillofacial Surg. 2003;32(5): 548-52. doi: 10.0154/ijom.2003.0413

8. Polat HB, Ozan F, Kara I, Ozdemir H, Ay S. Prevalence of commonly found pathoses associated with mandibular impacted third molars based on panoramic radiographs in Turkish population. Oral Surg Oral Med Oral Pathol Oral Radiol Endod. 2008;105(6): e41-7. doi: 10.1016/j.tripleo.2008.02.013

9. Malkawi Z, Al-Omiri MK, Khtaisat A. Risk indicators of postoperative complications following surgical extraction of lower third molars. Med Princ Pract. 2011;20(4):321-25. doi: $10.1159 / 000324550$

10. Adeyemo WL. Do pathologies associated with impacted lower third molars justify prophylactic removal? A critical review of the literature. Oral Surg Oral Med Oral Pathol Oral Radiol Endod .2006; 102(4): 448-52. doi: 10.1016/j.tripleo.2005.08.015

11. Mettes TG, Nienhuijs ME, Van der Sanden WJ, Verdonschot EH, Plasschaert AJ. Interventions for treating asymptomatic impacted wisdom teeth in adolescents and adults. Cochrane Database Syst Rev. 2005 18; (2): CD003879. doi: 10.1002/14651858.CD003879.pub2

12. Stanley HR, Alattar M, Collett WK, Stringfellow HR Jr, Spiegel EH. Pathological sequelae of "neglected" impacted third molars. J Oral Pathol. 1988;17(3):113-7. PMID: 3135372

13. Kruger E, Thomson WM, Konthasinghe P. Third molar outcomes from age 18 to 26 : findings from a populationbased New Zealand longitudinal study. Oral Surg Oral Med Oral Pathol Oral Radiol Endod. 2001;92(2):150-5. doi:10.1067/moe.2001.115461
14. Chaparro-Avendaño AV, Pérez-García $S$, ValmasedaCastellón E, Berini-Aytés L, Gay-Escoda C. Morbidity of third molar extraction in patients between 12 and 18 years of age. Med Oral Patol Oral Cir Bucal. 2005;10(5):422-31. PMID: 16264374

15. Krishnan B, El-Sheikh MH, El-Gehani $R$, Orafi $H$. Indications for removal of impacted mandibular third molars: a single institutional experience in Libya. J Maxillofac Oral Surg. 2009; 8(3): 246-8. doi: 10.1007/s12663-009-0060-5

16. Odai ED, Obuekwe ON. Study of indications for disimpaction of mandibular third molar and the frequently associated complications following such treatments. Ann Med Surg Prac. 2016;1(1):44-50.

17. Khan M, Mehmboob B, Katpar S. Extraction of wisdom teeth under general anesthesia- A study. JKCD. 2014;5(1):20-4.

18. Ishfaq M, Wahid A, Rahim AU, Munim A. Patterns and presentations of impacted mandibular third molars subjected to removal at Khyber College of Dentistry Peshawar. Pak Oral Dent J. 2006;26(2):221-6.

19. Rahman SA, Alam MK, Woei KC, Shaari R. Pattern of angulations of mandibular third molar impaction in a Malaysian population: A retrospective radiographic investigation. Int Med J. 2014;21(1):120-2.

20. Shahzad MA, Marath MA, Chatha MR, Sohail A. Evaluation of patterns of mandibular third molar impactions and associated pathologies. Pak Oral Dent J. 2016;36(2):92-6.

21. Hazza'a A, Bataineh A, Odat A. Angulation of mandibular third molar as a predictive factor for pericoronitis. JCDP. 2009;10(3):51-8. PMID: 19430626

22. Oenning AC, Neves FS, Alencar PN, Prado RF, Groppo $F C$, Haiter-Neto F. External root resorption of the second molar accociated with third molar impaction: Comparison of panoramic radiography and cone beam computed tomography. J Oral Maxillofac Surg. 2014;72(8):1444-55. doi: 10.1016/j.joms.2014.03.023

23. Abdulai $A E$, Nauman IK, Sackeyfio J, Hewlett S. Indications for surgical extraction of third molars: a hospital-based study in Accra, Ghana. Int J Med Biomed Res. 2014;3(3):155-60. 